\title{
Determining the differential preferences of users of two fluoride-free water options in rural Ethiopia
}

\author{
Alexandra C. Huber • Hans-Joachim Mosler
}

Received: 23 March 2012 / Accepted: 29 August 2012 /Published online: 21 September 2012

(C) Springer-Verlag 2012

\begin{abstract}
Aim In the Ethiopian Rift Valley, 8.5 million people depend on water sources with excessive fluoride. In one rural village, a fluoride-removal community filter was implemented; a personalized reminder was distributed to change people's behavior and increase the usage of the in-village community filter. During this promotion phase, an alternative fluorideremoval option was installed in a neighboring village.

This study examines psychological factors that explain the differences in preference between the two options and their influence on the usage of the different sources. In addition, the effectiveness of the applied behavior change technique, a personalized reminder, on the use of the invillage community filter was analyzed.

Subject and methods In a complete longitudinal survey, 180 households, with access to both mitigation options, were interviewed through structured, face-to-face interviews. Logistic regressions were carried out to reveal factors predicting the usage of the two mitigation options and the effect of the implemented behavior change intervention.

Results The results showed that the better the taste, the lower the effort and the lower the costs for using the invillage community filter are perceived; in addition, the lower the perceived vulnerability to contract disease, the more the in-village community filter is used. Moreover, it was found that the personalized reminder also had a positive effect on the usage of the in-village mitigation option. Conclusion Based on the results, possible recommendations for practitioners and researchers are made to help plan and implement mitigation options.
\end{abstract}

A. C. Huber $(\bowtie) \cdot$ H.-J. Mosler

Eawag: Swiss Federal Institute of Aquatic

Science and Technology,

Ueberlandstrasse 133, PO Box 611, 8600 Duebendorf, Switzerland

e-mail: alexandra.claudia.huber@gmail.com
Keywords Fluoride removal filter - Behavior change · Perceived costs $\cdot$ Perceived taste $\cdot$ Effort $\cdot$ Personalized reminder intervention

\section{Introduction}

The supply of safe water options is a great challenge, especially in developing countries. Worldwide, hundreds of millions of people rely on drinking water polluted by geogenic contaminants such as fluoride or arsenic. In Ethiopia, 8.5 million people are at risk of developing endemic fluorosis resulting from excessive fluoride uptake through water (Tekle-Haimanot et al. 2006). Fluoride is a naturally occurring mineral that becomes a crucial contaminant of ground and surface water sources at excessive levels. Dissolved in water, fluoride develops its toxic effect on the human body by affecting mainly calcium-containing body parts (McDonagh et al. 2000). As a result, being exposed to high fluoride concentrations in water and having an excessive fluoride intake leads to the development of dental and skeletal fluorosis. The symptoms of dental fluorosis are irregular brown patches on the teeth; symptoms of skeletal fluorosis are bone deformity, limitation of joint movements, and, in the last stage of the disease, crippling. Moreover, people suffering from this disease face psychosocial impacts such as social exclusion and discrimination (Tekle-Haimanot et al. 2006). Because the medical treatment of fluorosis is very difficult and mostly ineffective, the prevention of fluoride uptake becomes crucial.

To prevent fluoride uptake, people have to stop consuming as much fluoride-contaminated water as possible. For this reason, fluoride-free mitigation options need to be implemented in highly affected areas. One possible option for defluoridation is filtering fluoride using the Nakuru technique, which is comprised of a filter material that mixes bone char (charred animal bones) with calcium-phosphate 
pellets (Korir et al. 2009). Filtering fluoride with bone char has been found to be an efficient, simple, and comparatively low-cost technology, which is applicable at the household and community level (Kloos and Tekle-Haimanot 1999).

However, just making fluoride-free water available - for example, by installing a community filter-is not enough. People might not consume sufficient filtered water, as using a new technology implies behavior change, from collecting water at an untreated water source to collecting water at a newly implemented safe water source. People might have difficulties adapting to the new behavior because of many different psychological, social, or situational barriers. Therefore, it is crucial that technical solutions are accompanied by behavior change interventions that facilitate the uptake of the new behavior and change people's beliefs about the new behavior. Another important point, which should be taken into account when analyzing behavior change after implementation of a new technology, is that people might have various alternative behaviors to choose from. There are always at least two different alternatives: collecting raw water and collecting treated water. If various safe water options are installed in one area, people have even more alternatives. Therefore, it is important for implementers to know not only which safe water option is more sustainable, but also which option is preferred, and for what reason.

\section{Preference factors}

To gain insight into why households take up a new behavior and why they prefer a certain alternative, it is important to assess the underlying psychological factors of behavior. Various theories and models of health behavior change provide a wide range of behavioral factors, which should be analyzed. However, health behavior adaptation in developing countries - for example, the uptake of a new safe drinking-water option - was carefully depicted in Mosler's systematic approach to behavior change in developing countries (Mosler 2012). To determine the behavioral factors influencing preference and use of an option, we drew on the RANAS Model (risk, attitudes, norms, abilities, and selfregulation) of Mosler (2012). In this model, psychological factors are ordered in five different blocks-risk factors, attitudinal factors, normative factors, ability factors, and self-regulation factors-which comprise all the factors necessary to explain health behavior change (see Albarracín, et al. 2005). Risk factors are divided into perceived vulnerability (a person's subjective perception of his or her risk of contracting a disease) and perceived severity (a person's perception of the seriousness of the consequences of contracting a disease). In addition, a person should have an understanding (knowledge) of how she or he could be affected by a disease through environmental conditions. As attitudinal factors, the taste of the water, perceived costs, and perceived distance are considered, as well as how effortful it is to collect the water from the option. Furthermore, the overall affect refers to feelings that arise when thinking about the behavior. Normative factors regard the descriptive norm (perceptions of which behaviors are typically performed) and the injunctive norm (perceptions of which behaviors are typically approved or disapproved by important others). The ability factors are represented by selfefficacy, which is the belief in one's capabilities to organize and execute the course of actions required to manage prospective situations. Finally, self-regulation factors put a behavior into practice and help to maintain it; planning is of use as the person plans how to cope with distractions and barriers. In addition, to perform a behavior continuously, the person has to be committed to doing so, and the behavior needs to be remembered at critical moments.

In a study about the use of arsenic-safe water options, it was shown that preference and use of different options can be explained quite well using these behavioral factors (Inauen and Mosler 2010). In the present study, we focused on differences between two options to determine which factors have to be particularly taken into account when introducing a certain choice.

\section{Personalized reminders}

Practitioners working in the field of public health in the developing context agree more and more that simply implementing a new technology (e.g., a safe water option) is not enough. People might not use the newly implemented mitigation option for various reasons, which is why it is crucial to combine the provision of hardware with behavior change techniques. Numerous public health interventions have proven to be effective. One intervention technique to change people's daily behavior is the provision of reminders. Reminders or prompts are visual or oral external memory aids that point a person to a certain targeted behavior (Tobias 2009). Tobias (2009) underlines two important main requirements for a reminder to be effective: (1) the information on the reminder must be clearly understandable, so that the person knows what behavior is desired and (2) the reminder must be visible and located where the behavior should be initiated. Various studies in different fields (e.g., pro-environmental behavior or health behavior) have proven, consistently, the effectiveness of prompts as behavior-changing interventions (e.g., Holland et al. 2006; Lewis and Eves 2012). However, to our knowledge, there has not been much research on personalized reminders and their effectiveness to bind people to a certain behavior option instead of an alternative. This study evaluates the effectiveness of a personalized photo reminder on the collection of water at an in-village community filter. 
In general, the present study aims to answer three research questions: (1) In which psychological factors do the two preference groups differ? (2) Which psychological factors influence the use of either the in-village community filter or the alternative source? (3) Does the personalized reminder influence people's preference?

\section{Methods}

To assess the possible psychological factors that influenced the preference of the two fluoride mitigation options, a longitudinal survey was employed. In May 2010, a fluoride-removal community filter using the Nakuru technique was installed in one rural village, Weyo Gabriel, Oromia Region. The community filter was placed in the center of the village, next to the main public raw water source, a small piped water supply containing $3 \mathrm{mg} / \mathrm{L}$ of fluoride. The water tariff was set by the local water committee at $0.50 \mathrm{ETB}^{1}$ per $20-1$ jerrycan. The tariff for fluoridetreated water is twice as high as the tariff for raw water in this village. The community filter is filled with $600 \mathrm{~L}$ of bone char and $900 \mathrm{~L}$ of calcium phosphate pellets. After installation and testing of the filter, the project team organized an inauguration festival for all community members, where speeches were held and a local theater group performed a play to inform people about the fluoride problem. On inauguration day, everybody was allowed to collect water from the new community filter free of charge. The first panel survey took place in September 2010 (P1) and was followed by a first intervention phase (INT1), a persuasion campaign tackling people's perceived vulnerability and perceived price, in October 2010. The analyzed results from INT1 are currently submitted elsewhere. In December 2010, the second panel survey was conducted (P2), followed by the second intervention phase (INT2) and a second postintervention survey (P3) in February 2011. For an overview of the study design see Fig. 1. For the present study, P2, INT2, and P3 are analyzed. During the second intervention phase (INT2), a private organization opened a business and installed another fluoride-removal option in the same project area, approximately $3 \mathrm{~km}$ from the project community filter (CF). The new alternative option was a reverse osmosis (RO) treatment plant, from which the fluoride-free water is sold to the public at a tariff of 0.25 ETB per 20-L jerrycan.

Study area and sample

The study area is the village of Weyo Gabriel, a typical rural village in the Northern Rift Valley region. Most of its

\footnotetext{
${ }^{1} 1$ ETB (Ethiopian Birr) $=6$ US cents (exchange rate on June 13, 2011).
}

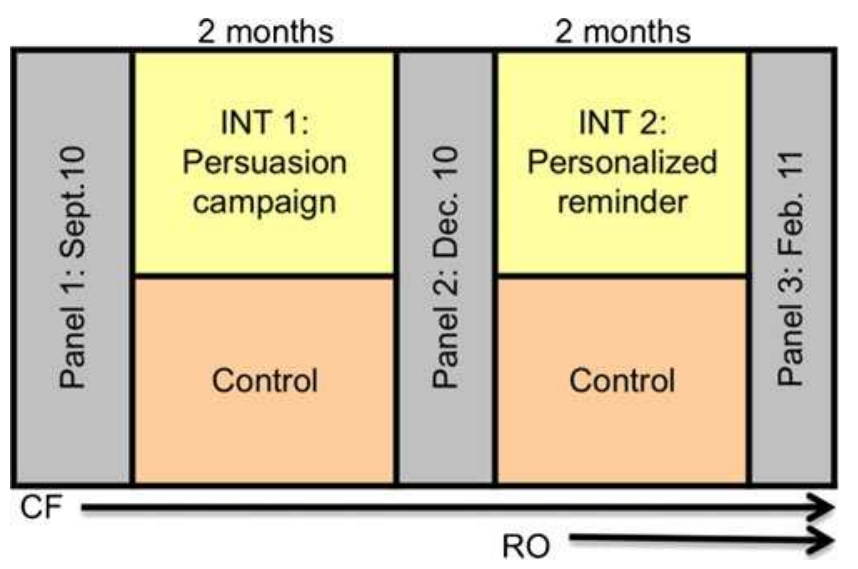

Fig. 1 Overview of study design including three panel phases and two intervention phases and the installation of the in-village community filter $(C F)$ and the alternative reverse osmosis filter $(R O)$

inhabitants are self-sustaining farmers, who live very basically, without running water, electricity, or proper sanitation facilities, in mud and stone houses. The main water sources are public boreholes and private hand-dug wells, which vary in their fluoride concentration between 2 and $18 \mathrm{mg} / \mathrm{L}$. These levels of fluoride content are above the World Health Organization (2004) guideline value of $1.5 \mathrm{mg} / \mathrm{L}$ (Tekle-Haimanot et al. 2006).

The goal of the study was to have a complete survey of all households in the project village. The regional office confirmed a total number of approximately 320 households, from which 120 households were excluded because they owned a fluoride-removal household filter and were part of another study (see Huber et al. 2011a, b). Of the 200 households targeted - the aim was a complete survey - 180 households were found during the first panel survey (P1). In the two follow-up panels (P2 and P3), eight households were no longer traceable due to migration to town; as such, only 172 households were interviewed.

\section{Procedure and intervention}

Because of high illiteracy among the respondents, the data collection was carried out through structured, face-to-face interviews. Ten local college students were recruited as interviewers. Before each survey, the interviewer team attended a 4-day training workshop, which consisted of information about fluoride, fluorosis, and the implemented community filter; interviewing skills (e.g., how to conduct the interview and how to avoid asking suggestive questions); and social skills (e.g., how to approach a household and how to handle negative reactions). The households were visited without preannouncement, informed about the study, and asked for consent. The rejection rate was $0 \%$ in all panels. The interview was held with the person responsible 
for water collection in the household. During the surveys, the interviewer team was supervised and monitored.

After the post-intervention survey (P2), the gathered data was analyzed to evaluate the effectiveness of the first intervention phase and to investigate which follow-up intervention was applied best in order to gain more CF users and avoid relapsing to old behavior (collecting water at the raw water source). The research team, together with the local non-governmental organization, developed the second intervention, a personalized photo reminder. One week before the intervention phase, the community facilitator of the village went to visit as many households as possible to announce the upcoming promotion. He informed the households that in the coming week, a photographer could come to the $\mathrm{CF}$ to take photos of people fetching fluoride-free water. People who collected water at the CF the following week were asked if they wanted their photo to be taken. The photos were printed on the reminder and a slogan was added: "Always drink and cook with water from the community filter." The reminders were distributed by the caretaker of the filter. The goals of the intervention were (1) to gain new users by giving them an incentive and (2) to help people remember to collect and consume treated water. During the second post-intervention survey (P3), interviewers checked if households had a photo reminder displayed; 48 households had one or more photos hanging in their house (Fig. 2).

\section{Questionnaire and measures}

The structured questionnaires for all panel surveys were designed in English and then translated into two locally spoken languages (Amharic and Oromic), back-translated by two assistants and, finally, revised by the interviewers during training. The questionnaires were pretested with 20 households to ensure applicability and understanding. The questionnaires were designed to cover water collection at different alternative sources, household water consumption, the psychological factors described previously, and sociodemographics. Most of the questions were quantitatively measured with 9-point Likert scales for bipolar items and 5-point Likert scales for unipolar items. Factor analyses and reliability analyses (calculating Cronbach's alpha) were executed to scale multiple items.

Usage of treated water source: The dependent dichotomous variable covers two groups: group 1 used water from the $\mathrm{CF}$ and group 2 preferred collecting water at an alternative source, the new RO plant. Respondents who stated that their households consumed at least $50 \%$ more from the $\mathrm{CF}$ than the new alternative were allocated to group 1 , whereas households that consumed $50 \%$ or more from the alternative source compared to CF were allocated to group 2. Household that showed no preference for either source (consumed $50 \%$ of each or $0 \%$ of each) were excluded from the analysis. The current household consumption of treated water was quantified in terms of the percentage of drinking filtered water and cooking with filtered water. First, the person responsible for collecting water reported the weekly purchase of treated water at the CF and the purchase at the new alternative source. Second, the respondent was asked to show the interviewer a regularly used cup, jug, or glass and to assess how many of these cups the entire family drank per day. With the interviewer's estimation of the volume of the named vessel, the total liters consumed per day and household could be calculated. In the end, the percentage of each water source (treated water from the community filter, treated water from the alternative source, and raw water) compared to total water consumption was computed.
Fig. 2 Personalized reminder: Picture of a woman collecting water at the in-village community filter together with the following message in Oromic and Amharic: "Always drink and cook with water from the community filter." The woman will take this picture to her home as a reminder

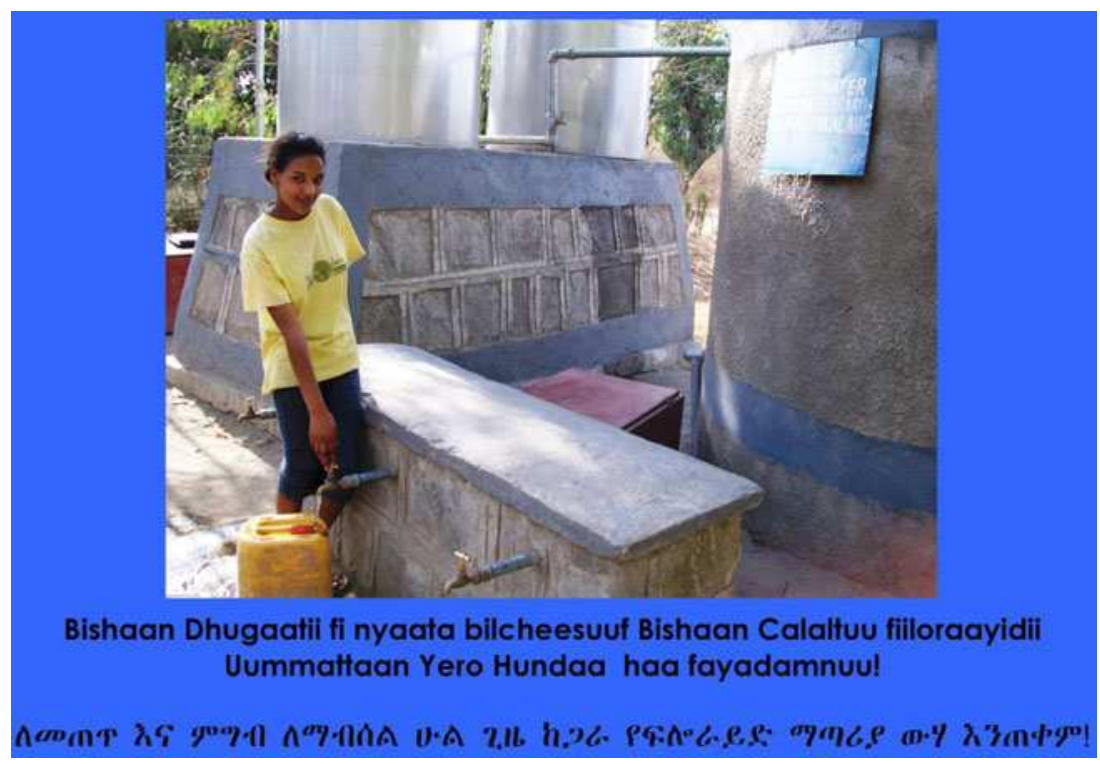


Concerning preference factors, all independent variables, except perceived costs, perceived distance, and forgetting, were measured with multiple items, and therefore, included in the analyses as scales. In Table 1, for each independent variable, an example item is displayed. The knowledge variable was measured with five Kprim-style multiplechoice questions (Krebs 2002). This method is applied if several elements of a subject (e.g., knowledge about fluoride, disease, and prevention of the disease) influence an issue (e.g., people's overall factual knowledge). All items surveying the psychological factors were measured in reference to the collection of water at the project community filter.

\section{Results}

The interviews were held with the person responsible for obtaining water; this person was female in $78.6 \%$ of the cases and mainly identified as a housewife (48.3\%), working in agriculture (32.2\%), or informally employed. The mean age of the respondents was 34.7 years (range, 980 years). In $57.8 \%$, the interviews were held in Oromic, and $42.2 \%$ were held in Amharic. The majority of the interviewees stated that they were Ethiopian Orthodox $(84.4 \%)$, and there were small groups of Muslims (10\%) and Protestants $(5.6 \%)$. On average, the highest completed school grade was 2 years (range, $0-12$ years). However, $60.6 \%$ were unable to read or write. The mean family size of the questioned households was five people, ranging from 1 to 12 people living in one household.

At P2, the second panel survey prior to the investigated intervention phase INT2 (see Fig. 1), $34.3 \%$ of 172 households stated they only consumed (drinking and cooking) treated water from the $\mathrm{CF}$. An average of $65 \%(\mathrm{SD}=$ $33.8 \%$ ) of the total water consumption was treated water. After the implementation of the new alternative source and the behavior change intervention (personalized reminder), the average consumption of treated water increased to $87.1 \%$ $(\mathrm{SD}=24.0 \%)$. This increase is significant $(t=-7.26, \mathrm{df}=$ $168, p=.000)$ and represents a large effect $(r=0.489)$. However, $18.6 \%(n=32)$ of the total sample preferred the new alternative source at $\mathrm{P} 3$, whereas $55.8 \%$ still preferred to collect water at the CF $(n=96) ; 25.6 \%$ of the respondents did not have any preference (they collected the same amount of water at both sources). The actual consumption at the invillage $\mathrm{CF}$ was measured every day and reported to the $\mathrm{NGO}$ and research group. The decrease of in-village $\mathrm{CF}$ water consumption was visible after the installation of the RO plant in the numbers of sold water per day.

The means and standard deviations of the observed psychological factors for each preference group are displayed in Table 2. To answer research question 1, for comparing the

Table 1 Example items for independent variables

\begin{tabular}{|c|c|c|c|}
\hline Scale/factor & Example items & Lowest value & Highest value \\
\hline Vulnerability & $\begin{array}{l}\text { How high or low do you feel are the chances that } \\
\text { you could contract fluorosis? The chances are... }\end{array}$ & $-1=$ much lower than average & $\begin{array}{l}1 \text { = much higher } \\
\text { than average }\end{array}$ \\
\hline Severity & $\begin{array}{l}\text { Imagine that you contracted skeletal fluorosis; how } \\
\text { severe would be the impact on your economic situation? }\end{array}$ & $0=$ not severe at all & $1=$ very severe \\
\hline Knowledge & What is fluoride - a chemical, aworm, a parasite, a stone? & \multicolumn{2}{|c|}{$\begin{array}{l}4 \text { multiple choice answers; for each } 0=\text { answer } \\
\text { was wrong } 1=\text { answer was right }\end{array}$} \\
\hline Overall affect & $\begin{array}{l}\text { How much do you like or dislike fetching } \\
\text { water at the community filter? }\end{array}$ & $-1=\mathrm{I}$ dislike it very much & $1=\mathrm{I}$ like it very much \\
\hline Taste & $\begin{array}{l}\text { How much do you like or dislike the taste of food } \\
\text { cooked with water from the community filter? }\end{array}$ & $-1=\mathrm{I}$ dislike it very much & $1=\mathrm{I}$ like it very much \\
\hline Perceived costs & $\begin{array}{l}\text { Do you think that } 0.5 \text { Birr for one } 20-\mathrm{L} \text { jerrycan of } \\
\text { fluoride-free water is too cheap, too expensive, or right? }\end{array}$ & $-1=$ much too expensive & $1=$ much too cheap \\
\hline Perceived distance & Is the community filter far from your home? & $0=$ not far at all & $1=$ very far \\
\hline Effort & Do you think using the community filter is time-consuming? & $0=$ not time-consuming at all & $1=$ very time-consuming \\
\hline Descriptive norm & $\begin{array}{l}\text { How many people in your community fetch } \\
\text { water at the community filter? }\end{array}$ & $0=$ almost nobody & $1=$ almost all \\
\hline Injunctive norm & $\begin{array}{l}\text { Most of my relatives think that I should fetch } \\
\text { water at the community filter }\end{array}$ & $-1=\mathrm{I}$ totally disagree & $1=\mathrm{I}$ totally agree \\
\hline Self-efficacy & $\begin{array}{l}\text { I am able to fetch enough water from the } \\
\text { community filter for the whole family }\end{array}$ & $-1=\mathrm{I}$ totally disagree & $1=\mathrm{I}$ totally agree \\
\hline Planning & $\begin{array}{l}\text { Have you made a detailed plan regarding what to } \\
\text { do if the community filter gets broken? }\end{array}$ & $0=$ no plan at all & $1=$ a very detailed plan \\
\hline Forgetting & $\begin{array}{l}\text { How often does it happen that you forget to } \\
\text { fetch water at the community filter? }\end{array}$ & $0=$ almost never & $1=$ almost always \\
\hline Commitment & $\begin{array}{l}\text { How committed do you feel to fetching } \\
\text { water at the community filter? }\end{array}$ & $0=$ not at all & $1=$ very committed \\
\hline
\end{tabular}


Table 2 Cronbach's alpha for scales, means and standard deviations for group 1 (prefers in-village community filter) and group 2 (prefers alternative source) and independent sample t-test statistics for comparing means between group 1 and group 2

\begin{tabular}{|c|c|c|c|c|c|c|c|c|c|c|}
\hline \multirow[t]{2}{*}{ Factor block } & \multirow[t]{2}{*}{ Factor } & \multirow{2}{*}{$\begin{array}{l}\text { Scale } \\
\alpha\end{array}$} & \multicolumn{2}{|l|}{ Group 1} & \multicolumn{2}{|l|}{ Group 2} & \multicolumn{4}{|c|}{ t-test statistics } \\
\hline & & & M & SD & M & SD & $\mathrm{t}$ & $\mathrm{df}$ & $p$ & $r$ \\
\hline \multirow[t]{3}{*}{ Risk factors } & Vulnerability & 0.898 & -0.190 & 0.255 & -0.065 & 0.215 & -2.495 & 126 & 0.014 & 0.217 \\
\hline & Severity & 0.742 & 0.912 & 0.101 & 0.919 & 0.150 & -0.332 & 126 & 0.740 & 0.029 \\
\hline & Knowledge & - & 0.580 & 0.209 & 0.709 & 0.199 & -3.046 & 122 & 0.003 & 0.266 \\
\hline \multirow[t]{5}{*}{ Attitude factors } & Overall affect & 0.908 & 0.836 & 0.137 & 0.471 & 0.448 & 7.088 & 126 & 0.000 & 0.534 \\
\hline & Taste & 0.901 & 0.804 & 0.208 & 0.219 & 0.574 & 8.499 & 126 & 0.000 & 0.604 \\
\hline & Perceived costs & - & 0.328 & 0.673 & 0.633 & 0.571 & -2.298 & 126 & 0.023 & 0.201 \\
\hline & Perceived distance & - & 0.609 & 0.251 & 0.586 & 0.243 & 0.461 & 126 & 0.654 & 0.041 \\
\hline & Effort & 0.688 & 0.747 & 0.204 & 0.699 & 0.262 & 1.076 & 126 & 0.284 & 0.095 \\
\hline \multirow[t]{2}{*}{ Norm factors } & Descriptive norm & 0.748 & 0.479 & 0.168 & 0.391 & 0.143 & 2.670 & 126 & 0.009 & 0.231 \\
\hline & Injunctive norm & 0.969 & 0.727 & 0.250 & 0.225 & 0.592 & 6.736 & 126 & 0.000 & 0.515 \\
\hline Ability factors & Self-efficacy & 0.884 & 0.729 & 0.205 & 0.364 & 0.426 & 6.472 & 126 & 0.000 & 0.500 \\
\hline \multirow[t]{3}{*}{ Self-regulation factors } & Planning & 0.850 & 0.587 & 0.191 & 0.365 & 0.209 & 5.547 & 126 & 0.000 & 0.443 \\
\hline & Forgetting & - & 0.060 & 0.198 & 0.344 & 0.405 & -5.258 & 126 & 0.000 & 0.424 \\
\hline & Commitment & 0.864 & 0.856 & 0.149 & 0.607 & 0.315 & 6.013 & 126 & 0.000 & 0.472 \\
\hline
\end{tabular}

Group $1(n=96)$, group $2(n=32)$

differences between the means of the two groups, independent sample t-tests were calculated. The results also can be found in Table 2.

Nearly all psychological factors differ significantly between the preference groups (Table 2). People who preferred the usage of the CF (group 1) felt significantly more vulnerable to contracting fluorosis than people who collected water at the alternative option; nevertheless, the effect is rather small $(r=0.217)$. Further, group 1 showed a significantly higher overall positive affect towards collecting water at the CF (with a large effect, $r=0.534$ ), perceived the taste of water from the $\mathrm{CF}$ as much better (with a large effect, $r=$ 0.604), showed a significantly higher injunctive norm, meaning that more people from their environment think they should collect water from the CF (also with a large effect, $r=0.515$ ), felt significantly more able to provide their family with treated water, had a higher self-efficacy (represented by a large effect, $r=0.500$ ), had considerably more detailed plans for overcoming barriers (showing a rather large effect, $r=0.443$ ), and felt more committed to using the in-village $\mathrm{CF}$ (with a large effect, $r=0.472$ ).

However, in three factors, the two groups do not differ significantly. People perceived skeletal and dental fluorosis as very severe in both groups. Unexpectedly, the groups also did not differ in perceived distance, meaning that both preference groups thought that the $\mathrm{CF}$ was somewhat close to their home. Moreover, the effort involved in collecting water at the CF was estimated equally low in both groups.

Households that preferred the alternative source (group 2), however, showed slightly higher knowledge about fluoride and fluorosis and its prevention than group 1, though represented by a rather small effect $(r=0.266)$. Moreover, group 2 perceived the costs for treated water at $\mathrm{CF}$ as much higher, even though the effect is rather weak $(r=0.201)$. In addition, people from group 2, by far, forgot more often to collect water from the $\mathrm{CF}$, which is represented with a rather large effect $(r=0.424)$.

To answer the second research question and evaluate the main influencing psychological factors that predict the use of either the in-village CF or the alternative source, a binary logistic regression was carried out (see Table 3). Because of the dichotomous dependent variable (use community filter or use alternative option), a logistic instead of linear regression was chosen. A forced entry method was used for the calculation of the regression, in order to include all factors from the behavior model. The results, displayed in Table 3, show which of the psychological factors determine the use of either one option or the other. After the calculation of the regression, an outlier analysis was undertaken, which resulted in the necessity to exclude four outliers. The eliminated cases showed residuals that exceeded more than two standard deviations and, therefore, would have been misclassified. The resulting regression model showed a high fit $($ Nagelkerke $=69.2 \%$ ) and was able to classify $86.7 \%$ of all cases correctly.

Four psychological factors contributed significantly to the prediction of the preference groups: perceived vulnerability, perceived taste of treated water, costs of treated water, and effort to collect treated water. The less vulnerable that people felt to contracting fluorosis, the more probable it was 
Table 3 Logistic regression analysis for variables predicting preference of safe water option $(1=$ uses in-village community filter more, $0=$ uses alternative source more)

\begin{tabular}{|c|c|c|c|c|c|c|}
\hline Factor block & Factor & $\mathrm{B}$ & SE B & $\operatorname{Exp}(\mathrm{B})$ & $\mathrm{p}$ & CI $(95 \%)$ for $\operatorname{Exp}(\mathrm{B})$ \\
\hline \multirow[t]{3}{*}{ Risk factors } & Vulnerability & -3.844 & 1.943 & 0.021 & 0.048 & $(0,0.964)$ \\
\hline & Severity & -1.212 & 3.950 & 0.298 & 0.759 & $(0,658.0)$ \\
\hline & Knowledge & -1.282 & 2.818 & 0.278 & 0.649 & $(0,69.56)$ \\
\hline \multirow[t]{5}{*}{ Attitude factors } & Overall affect & 3.614 & 2.970 & 37.132 & 0.224 & $(0.11,12,537)$ \\
\hline & Taste & 5.049 & 2.018 & 155.889 & 0.012 & $(2.98,8137.9)$ \\
\hline & Perceived costs & -2.757 & 1.211 & 0.063 & 0.023 & $(0,0.681)$ \\
\hline & Perceived distance & 2.218 & 2.181 & 9.188 & 0.309 & $(0.13,660.7)$ \\
\hline & Effort & -7.008 & 2.967 & 0.001 & 0.018 & $(0,0.303)$ \\
\hline \multirow[t]{2}{*}{ Norm factors } & Descriptive norm & 3.986 & 3.051 & 53.841 & 0.191 & $(0.14,21296.1)$ \\
\hline & Injunctive norm & -0.525 & 2.157 & 0.592 & 0.808 & $(0,40.59)$ \\
\hline Ability factors & Self-efficacy & -3.235 & 2.705 & 0.039 & 0.232 & $(0,7.89)$ \\
\hline \multirow[t]{3}{*}{ Self-regulation factors } & Planning & 4.173 & 3.058 & 64.940 & 0.172 & $(0.16,26010.9)$ \\
\hline & Forgetting & -0.173 & 1.245 & 0.841 & 0.890 & $(0.01,9.66)$ \\
\hline & Commitment & 3.021 & 3.15 & 20.520 & 0.337 & $(0.04,9843.52)$ \\
\hline Constant & & -8.304 & 4.514 & - & 0.066 & - \\
\hline
\end{tabular}

Nagelkerke $R^{2}=0.692$, LR $-\chi^{2}=73.62$ with $d f=14(p=.000), n=120$. A forced entry method was used for the calculation

that they preferred consuming water from the CF. A positive perceived taste of the water increased the possibility that they would collect more water at the CF. The less expensive that people perceived the price to be at the $\mathrm{CF}$, the more likely it was that they would collect water there. Furthermore, the likelihood that they would collect more water at the $\mathrm{CF}$ increased if people perceived that collecting water there took less effort. None of the norm factors or the ability and self-regulation factors significantly contributed to the explanation of the preference groups. It is noteworthy that the psychological factors self-efficacy, injunctive norm, overall affect, and commitment intercorrelate rather highly $(r>0.60)$. Therefore, conclusions regarding the most influential factors should be made with caution. The intercorrelation indicates that all of the factors, on their own, might have a much stronger influence on people's preference, even though they may not reach a significant result in the final regression analysis.

To test the effectiveness of the implemented behavior change intervention (personalized reminder) and answer research question 3, a further logistic regression was calculated. The user group (option 1 or 2) was considered a dependent variable for calculation, and intervention (was a personalized reminder visible in the house or not) was considered an independent variable. The calculated model showed a model fit of $14.3 \%$ and successfully classified $77.4 \%$ of all cases. Furthermore, the regression revealed that having a personalized reminder at home significantly increased the probability of using the water at the in-village community filter $(B=2.56, S E B=1.04, \operatorname{Exp}(B)=12.88$, $p=.014)$.

\section{Discussion}

With regard to research question 1 , the two user groups were found to differ significantly in nearly all psychological factors, which implies that there were definitely differences in people's perceptions towards the two water options and that these differences influenced which option they chose. However, to predict which option people choose, it is not only necessary to analyze in which psychological factor the user groups differ but also, which of the psychological factors significantly influence people's preference (research question 2). Regarding people's risk perception, both groups were aware of the severity of dental and skeletal fluorosis; however, those who preferred to collect water at the CF felt significantly less vulnerable to contracting fluorosis, which significantly predicted their preference. There might be two reasons for this result. One possible explanation is that people who collected water at the sustainable source, which had existed for nearly 2 years and was promoted with different campaigns, felt safe using that water and, therefore, felt less vulnerable to contracting fluorosis. People who consumed water from the new alternative, which was not promoted and about which they did not have any information, might not be $100 \%$ certain about the effective prevention of fluorosis by consuming that water.

The two preference groups differed in attitudinal factors as well. People who preferred the CF liked collecting water there more and also enjoyed the taste of the water more than the other group. It has been found in many consumer research studies that positive attitudes towards a product relate positively to purchase intentions and behavior (e.g., Smith et 
al. 2008). A reverse causality is also possible in this case. The self-perception theory states that people must have a positive attitude towards an object they bought or consumed (Bem 1972). In addition, the perception of the taste of the water was found to influence people's preference of different water types. Researchers found that most preferred water types have medium levels of mineralization and are perceived as tasteless and cooler (Teillet et al. 2009). Furthermore, people who collected water at the CF perceived the price of filtered water as a lot less than the other group did. This might be a result of the first intervention, when people's perception of price was successfully tackled with persuasion (see Huber et al. 2011a, b). Perceived price is a crucial influencing factor of the choices that people make; marketing researchers often find that price perception influences purchase (e.g., Monroe 1973; Lichtenstein et al. 1993).

Not unexpectedly, the two preference groups showed significant differences in both norm factors as well. The descriptive and injunctive norms were significantly higher in the group of people who preferred the more sustainable water source. Consumer researchers also have focused on the role of injunctive and descriptive norms influencing consumer preferences and have found a positive relationship between norms and product preference (e.g., Smith et al. 2008). The higher descriptive norm also can be explained by the fact that people who used the CF more often also more frequently catch sight of important others collecting water there. Although not significantly predicting the preference, the influence of descriptive norm on behavior should not be underestimated. Various studies, also in the development context of safe drinking water, have found the descriptive norm to predict health behavior (e.g., Mosler et al. 2010).

People's abilities and self-regulation factors were found to be significantly higher in the group preferring the CF, even though they were not found to be significant predictors in the regression. As Kiesler and Sakumura (1966) already pointed out, individuals who are bound or committed to a certain behavior avoid behaviors that contradict their commitment and, moreover, are willing to perform behaviors that are coherent with their commitment. Therefore, the high commitment (towards the community filter) in group 1 is not surprising and supports former research. Consumer researchers have found that even if the purchase of a product evokes health risks (e.g., buying chicken during the chicken flu), a high commitment towards the product leads to an increase in consumption (Graffeo et al. 2009).

Finally, the implemented behavior change intervention, the personalized reminder, was found to influence people's preference positively (research question 3). People who took a photo during the promotion and hung up the reminder in their house preferred collecting water at the CF. The goal of the reminder was to bind people to a behavior that could be performed sustainably and not only for a short time. While taking people's pictures in front of the CF must be one reason for its effectiveness, research on how reminders or prompts operate psychologically is still rare. Mosler and Tobias (2007), however, postulate that the stronger a person feels committed to perform a certain behavior, the more probable it is that a situational cue, like a prompt, reminds the person of the behavior and, therefore, urges the person to act. This implies that a displayed reminder is able to induce commitment and, as soon the commitment is made, the reminder deploys a state of tension within the person if the behavior is not performed (Mosler and Tobias 2007).

\section{Limitations of the study and future research}

The present study has some limitations. First of all, it is important to bear in mind that field studies entail unforeseeable events and complications. However, such unexpected incidents can be very interesting and important to evaluate. One limitation of the study is the lack of psychological data regarding the collection at the new alternative, lesssustainable source. All psychological factors depicted in the survey are only measured in regard to the usage of the $\mathrm{CF}$, mainly because the research team was unaware of the implementation of the new safe water option. For future preference studies, it is advisable to evaluate the psychological factors in regard to all alternative behaviors (i.e., the collection and consumption of raw water).

A further limitation is the dependent behavior preference variable, which relies on self-reporting. Self-reported data is always at risk of being socially biased, especially if questioned during an interview. Discrepancies between self-reported behavior and actual performance are known regarding hand washing or water treatment behaviors (e.g. Halder et al. 2010; Arnold et al. 2009). However, due to the high illiteracy rate, interviews were the only possible survey method. The interviewers were trained intensively before each survey and understood the importance of reducing the desirability bias. Regardless, respondents did not find it odd or inconvenient to declare that they also collected water from the alternative option, and the bias is deniable regarding the variance found in the dependent and independent variables.

Finally, it should be mentioned that the longitudinal data was used only to define the preference group and not for the regression analysis. The independent predictors were measured at P3, after the implementation of the new water option and the behavior change technique. Therefore, the results should be carefully interpreted. In a future study, it would be better to (1) investigate the behavior and psychological factors towards each alternative behavior and (2) analyze the differences over time. Moreover, a future study should be conducted in other areas, with other samples, in order to generalize the results. 


\section{Implications for practice}

Gaining knowledge about what drives people to use an implemented mitigation option instead of using a newly implemented alternative is crucial for practitioners and implementers, especially if one of the options might be less sustainable than the other. If people change their behavior to collecting water at a possibly unsustainable source and later that source is not accessible anymore, it will be difficult to prevent people from relapsing to the consumption of unsafe, raw water. In the present study, the new alternative source, the RO plant, might be less sustainable than the implemented in-village CF. The raw material (e.g., animal bones) for producing bone char and calcium phosphate pellets used at the CF are locally available at low cost. Further, the income from the water sold at the CF can cover the salary of the caretaker, upcoming maintenance costs, and 50-75\% of the cost of replacement of new filter media. The implementers and suppliers, a local NGO, are responsible for the sustainable operation of the filter. By contrast, the newly implemented RO plant bears the risk of not being sustained. One reason is that RO is a high-tech process that requires skilled operators and electricity for operation. Therefore, the capital and operational costs are very high, which makes it impossible to sustain by selling the treated water for the same price as raw water. That is why it was important to promote the more sustainable option for preventing people from contracting fluorosis over the long term.

With knowledge about decisive predictors of mitigation option preferences, specific interventions can be designed to bind a target group to a possibly more sustainable option. If the psychological factors identified as significant are known, then they can be positively influenced through health promotion campaigns.

Attitude factors such as perceived taste, costs, and effort can be tackled with persuasive communication. As described in the Elaboration Likelihood Model of Petty et al. (2004), instrumental attitudes can be influenced with persuasion, using strong arguments, novel information, and positive outcome scenarios. For persuasion, not only the arguments are important, but also the peripheral cues. The messages should be delivered, for example, by health promoters who are perceived as competent, credible, and respected. In the case of perceived taste, one could increase their taste perception with arguments regarding health. Messages comparing the safe water to medicine might be helpful, by concluding that what is healthy does not always taste good (e.g., cod liver oil), or what tastes good is not always healthy (e.g., sweet soft drinks). Decreasing perceived price could be accomplished with messages saying that it is common that more expensive products also are of better quality, and vice versa (see the intervention study of Huber et al. 2011a, b). If perceived effort must be reduced, one could argue about the benefit of taking more time and effort to provide the subject's family with safe water. Promoters also could help people come up with a weekly plan of when, how, and how much water to collect, in order to save time.

To influence and change people's perceived norms, normative behavior change interventions should be applied. Descriptive norms can be tackled by highlighting how many important others perform the target behavior (Mosler 2012). Making a descriptive norm more salient can be achieved with a public commitment intervention, where people commit to performing a certain behavior and make their commitment public. This can be accomplished with a list of names or signatures of all safe water consumers, displayed at a frequently visited spot in the village. Another option, which would not require people to read or write, are publicly noticeable signs (e.g., a flag on the roof, a colorfully painted door), indicating the household's commitment to healthy behavior. According to DeLeon and Fuqua (1995), a public commitment initiates social consequences if the commitment displayed in public is not converted into actual behavior.

Last but not least, the study also shows that the implemented personalized reminder had a positive effect on the preference of the sustainable community filter. This result indicates that reminders or prompts are effective interventions to bind people to a certain behavior and help them not to forget it. Prompts are very popular behavior change interventions because they can be produced and distributed easily, are very cost-effective, and are accepted by all different types of target groups and cultures (De Young 1993; Thyer and Geller 1987).

In conclusion, the present study reveals important insights into why people choose a certain safe water option and how this preference can be influenced by behavior change techniques. Future studies should focus on all different alternative behaviors, so that the practitioners and implementers can identify crucial social, situational, and psychological factors and influence these with interventions to bind people to the most sustainable mitigation option.

Acknowledgments The present study is part of the Water Resource Quality (WRQ) project at EAWAG. First of all, we would like to extend thanks to Tesfaye Edosa, our field research assistant, and Feyisa Lemma, our social worker from the Oromo Self-Help Organization (OSHO). Without their professional input, valuable contribution, and great collaboration during the fieldwork, we would not have been able to accomplish the project. Second, our thanks go to all of our interviewers and health promoters, who contributed significantly to the success of the survey. Finally, we want to name the Swiss National Science Foundation (SNF) and the Swiss Agency for Development and Cooperation (DEZA) as the project's financial support.

Conflicts of interest The authors declare that they have no conflict of interest. 


\section{References}

Albarracín D, Gillette JC, Earl AN, Glasman LR, Durantini MR, Ho MH (2005) A test of major assumptions about behavior change: a comprehensive look at the effects of passive and active HIVprevention interventions since the beginning of the epidemic. Psychol Bull 131:856-897

Arnold B, Arana B, Mäusezahl D, Hubbard A, Colford J (2009) Evaluation of a pre-existing, 3-year household water treatment and handwashing intervention in rural Guatemala. Int J Hyg Envir Heal 38:1651-1661

Bem DJ (1972) Self-perception theory, vol 6. Academic, New York

De Young R (1993) Changing behavior and making it stick: the conceptualization and management of conservation behavior. Environ Behav 25:485-505

DeLeon IG, Fuqua RW (1995) The effects of public commitment and group feedback on curbside recycling. Environ Behav 27:233-250

Graffeo M, Savadori L, Tentori K, Bonini N, Rumiati R (2009) Consumer decision in the context of a food hazard: the effect of commitment. Mind Soc 8:59-76

Halder AK, Tronchet C, Akhter S, Bhuiya A, Johnston R, Luby SP (2010) Measures of handwashing behavior and indicators associated with hand hygiene in rural Bangladesh. BMC Publ Health 10:545-553

Holland R, Aarts H, Langendam D (2006) Breaking and creating habits on the working floor: a field-experiment on the power of implementation intentions. J Exp Soc Psychol 42:776-783

Huber AC, Bhend S, Mosler HJ (2011a) Determinants of exclusive consumption of fluoride-free water: a cross-sectional household study in rural Ethiopia. J Public Health 20:269-278. doi:10.1007/s10389-011$0445-\mathrm{z}$

Huber AC, Tobias R, Mosler HJ (2011) Evidence-based tailoring of persuasion campaigns: increasing fluoride-free water consumption in rural Ethiopia. Paper presented at the 25th Annual Conference of the European Health Psychology Society, Hersonissos, Crete, Greece, September 2011

Inauen J, Mosler H-J (2010) Risky consumption of drinking water: predicting the use of arsenic-safe drinking water options in Bangladesh. Oral presentation at the 27th International Congress of Applied Psychology, Melbourne, Australia, July, 2010

Kiesler CA, Sakumura J (1966) A test of a model for commitment. J Pers Soc Psychol 3:349-353

Kloos H, Tekle-Haimanot R (1999) Distribution of fluoride and fluorosis in Ethiopia and prospects for control. Trop Med Int Health 4:355-364

Korir H, Mueller K, Korir L, Kubai J, Wanja E, Wanjiku N, Waweru J, Mattle MJ, Osterwalder L, Johnson CA (2009) The development of bone char-based filters for the removal of fluoride from drinking water. Paper presented at the 34th WEDC International Conference, Addis Ababa, Ethiopia, May 2009
Krebs R (2002) Anleitung zur Herstellung von MC-Fragen und MCPrüfungen [Instructions for preparing $\mathrm{MC}$-questions and $\mathrm{MC}$ exams]. http://www.fnl.ch/LOBs/LOs_Public/MC_Anleitung.pdf. Accessed 6 March 2010

Lewis AL, Eves FF (2012) Testing the theory underlying the success of point-of-choice prompts: a multi-component stair climbing intervention. Psychol Sport Exercise 13:126-132

Lichtenstein DR, Ridgway NM, Netemeyer RG (1993) Price perceptions and consumer shopping behavior: a field study. J Marketing Res 30:234-245

McDonagh MS, Whiting PF, Wilson PM, Sutton AJ, Chestnutt I, Cooper J, Misso K, Bradley M, Treasure E, Kleinjnen J (2000) Systematic review of water fluoridation. Br Med J 321:855-859

Monroe KB (1973) Buyers' subjective perceptions of price. J Marketing Res 10:70-80

Mosler HJ (2012) A systematic approach to behavior change interventions for the water and sanitation sector in developing countries: a conceptual model, a review, and a guideline. Int J Environ Health Res. doi:10.1080/09603123.2011.650156

Mosler HJ, Tobias R (2007) How do commitments work? An agentbased simulation using data from a recycling campaign in Santiago de Cuba. Paper presented at the International Conference on Artificial Intelligence, Las Vegas, NV, June 2007

Mosler HJ, Blöchliger OR, Inauen J (2010) Personal, social, and situational factors influencing the consumption of drinking water from arsenic-safe deep tubewells in Bangladesh. J Environ Manage 91:1316-1323

Petty RE, Rucker DD, Bizer GY, Cacioppo JT (2004) The elaboration likelihood model of persuasion. In: Seiter JS, Gass RH (eds) Perspectives on persuasion, social influence, and compliance gaining. Pearson, Boston, pp 65-90

Smith JR, Terry DJ, Manstead ASR, Louis WR, Kotterman D, Wolfs J (2008) The attitude-behavior relationship in consumer conduct: the role of norms, past behavior, and self-identity. J Soc Psychol 148:311-333

Teillet E, Urbano C, Cordelle S, Schlich P (2009) Consumer perception and preference of bottled and tap water. J Sens Stud 25:463-480

Tekle-Haimanot R, Melaku Z, Kloos H, Reimann C, Fantaye W, Zerihun L, Bjorvatn K (2006) The geographic distribution of fluoride in surface and groundwater in Ethiopia with an emphasis on the Rift Valley. Sci Total Environ 367:182-190

Thyer BA, Geller ES (1987) The "buckle up" dashboard sticker: an effective environmental intervention for safety belt promotion. Environ Behav 19:484-494

Tobias R (2009) Changing behavior by memory aids: a social psychological model of prospective memory and habit development tested with dynamic field data. Psychol Rev 116:408-438

World Health Organization (2004) Guidelines for drinking-water quality, 3rd edn. World Health Organization, Geneva 